\title{
HYDRAULIC MODELS FOR THE SIMULATION OF FLOW ROUTING IN DRAINAGE CANALS
}

\author{
PANTELAKIS D. \\ ZISSIS Th. \\ ANASTASIADOU- PARTHENIOU E. \\ BALTAS E. *
}

\author{
Lab. of General and Agricultural Hydraulics and Land \\ Reclamation, Dept. of Hydraulics, Soil Science and Agricultural \\ Engineering, School of Agriculture \\ Aristotle University of Thessaloniki \\ 54124, Thesssaloniki, Greece
}

*to whom all correspondence should be addressed:

Accepted: $21 / 02 / 13$

e-mail: baltas@agro.auth.gr

\begin{abstract}
In order to design a network of drainage canals, it is essential to consider the excess water from the agricultural land (overland flow) and to evaluate the characteristics of flow routing, such as the flow depths and discharges in the system of tertiary and main drainage canals of various order. In this paper models based on the Saint-Venant equations are presented, simulating the flow routing in a system of drainage canals. In these models, the lateral inflow towards tertiary drainage canals is the overland flow from adjacent fields.
\end{abstract}

The Saint-Venant equations in their complete form (dynamic model) or in simplified forms, such as the diffusion wave equations (diffusion model) and the kinematic wave equations (kinematic model) are numerically solved by using the MacCormack explicit computational scheme which is a two-step predictor-corrector scheme, conditionally stable and convergent. In modeling flow through the system of drainage canals, emphasis was given to the simulation of flow at the junction points of two or more canals by applying the characteristic equations (negative and positive equations) in addition to the mass and energy conservation principles.

Applications of the models for the simulation of flow within the system of drainage canals, subject to lateral inflow owing to overland flow, were also conducted in order to study the effect of various parameters of the drainage canals, on the hydrographs' formation and also on the accuracy of the diffusion and kinematic equations in predicting flow in a drainage network.

KEYWORDS: drainage canals, routing models, Saint-Venant equations, MacCormack scheme.

\section{INTRODUCTION}

In order to design a system of drainage canals, it is essential to estimate the discharge rate and the flow depth at every point along the drainage canals. These hydraulic characteristics are affected among others by the duration and the intensity of rainfall that the irrigated fields receive, as well as the flow into the system of drainage canals. Overland flow is directed to the tertiary drainage canals and through the main system of drainage canals is directed downstream to the outlet of drainage system, as Figure 1 shows.

Flow routing in open channels especially in river networks has been studied in detail in the past and it may be approximated by hydrologic or hydraulic methods. Hydrologic methods, such as the Muskingum method, may be used (Chaudhry, 2008) in routing the flow in canal networks, but they are not able to simulate the backwater effects (Singh, 1996). Hydraulic methods may be used for flow routing simulation in a system of drainage canals, since in designing the canals their hydraulic and geometrical characteristics are considered known (Akan, 1985; Singh, 1996; Kesserwani et al., 2008). 
A lot of models using the hydraulic method are based on the numerical solution of the Saint-Venant equations, to simulate the unsteady one-dimensional flow routing through canal networks. In many cases the Preismman implicit computational scheme is applied to solve the Saint-Venant equations (Naidu et al., 1997; Chen et al., 2007). The Preismman scheme transforms the partial differential equations to a system of nonlinear algebraic equations which is solved by the Newton-Raphson method. Several researchers (Naidu et al., 1997; Sen and Garg, 2002; Islam et al., 2005) have presented various techniques to minimize the computational effort, which is significant for flow problems in canals networks. Explicit computational schemes for the short term simulation of flow routing, generated by intense rainfalls, through a network of drainage canals may be used to avoid complexities of the implicit schemes (Pantelakis et al., 2011).

In this research work, three numerical models are presented for the simulation of flow routing in a system of drainage canals. The tertiary canals are considered to receive the overland flow from the adjacent fields and thus overland flow is the lateral inflow towards the drainage canals. The flow routing models are based on the numerical solution of the one dimensional Saint-Venant equations in their complete form (dynamic model) and in their simplified forms, such as the diffusion wave equations (diffusion model) and the kinematic wave equations (kinematic model). The MacCormack explicit computational scheme, which is a two-step predictor-corrector scheme, conditionally stable and convergent, was used for the numerical solution of the above-mentioned equations. In modeling routing flow, emphasis was given to the simulation of flow at the junction points of two or more canals by applying the characteristic equations in addition to the mass and energy conservation principles. The three models were applied to a system of four drainage canals in order to determine the effect of the tertiary canals length, the canals bed slope and their roughness coefficient on the computed hydrographs and also the accuracy of the diffusion and kinematic equations in modeling flow in systems of drainage canals.

\section{GOVERNING EQUATIONS AND THE MACCORMACK SCHEME}

A typical system of drainage canals within surface irrigation systems is given in Figure 1. The overland flow is directed to the tertiary drainage ditches and then through the system of tertiary and main drainage canals of various order is conveyed to the outlet of the drainage network. The SaintVenant equations in their complete form and in their simplified forms (the diffusion and the kinematic equations) that describe one dimensional unsteady flow in a prismatic channel subject to lateral inflow, owing to overland flow, may be written in the following conservative Lax form:

$\frac{\partial \mathrm{U}}{\partial \mathrm{t}}+\frac{\partial \mathrm{F}}{\partial \mathrm{x}}=\mathrm{S}$

where

$$
\begin{aligned}
& U=\left(\begin{array}{l}
A \\
Q
\end{array}\right), \quad F=\left(\begin{array}{c}
Q \\
\frac{Q^{2}}{A}+g D A
\end{array}\right), \quad S=\left(\begin{array}{c}
Q p \\
g A\left(S_{o}-S_{f}\right)
\end{array}\right), \quad \text { (Dynamiq equations) } \\
& U=\left(\begin{array}{l}
A \\
0
\end{array}\right), \quad F=\left(\begin{array}{l}
Q \\
y
\end{array}\right), \quad S=\left(\begin{array}{c}
Q p \\
S_{o}-S_{f}
\end{array}\right), \quad \text { (Diffusion equations) } \\
& U=\left(\begin{array}{l}
A \\
0
\end{array}\right), \quad F=\left(\begin{array}{l}
Q \\
0
\end{array}\right), \quad S=\left(\begin{array}{c}
Q p \\
S_{o}-S_{f}
\end{array}\right), \quad \text { (Kinematic equations) }
\end{aligned}
$$

A is the area $\left(L^{2}\right), Q$ is the flow rate $\left(L^{3} T^{-1}\right), Q p$ is the lateral inflow from overland flow $\left(L^{3} L^{-2} T^{-1}\right), t$ is the time $(T), x$ is the distance $(L), g$ is the acceleration of gravity $\left(L T^{-2}\right), D$ is the distance between the center of the cross section and the free surface $(L), S_{o}$ is the bed slope $\left(L L^{-1}\right)$ and $S_{f}$ is the friction slope $\left(L L^{-1}\right)$ which is given by equation of Manning or Chezy.

The continuity and momentum equations written in the matrix form of Equations 1a and 2a,b,c express mathematically the principles of mass and momentum conservation. 


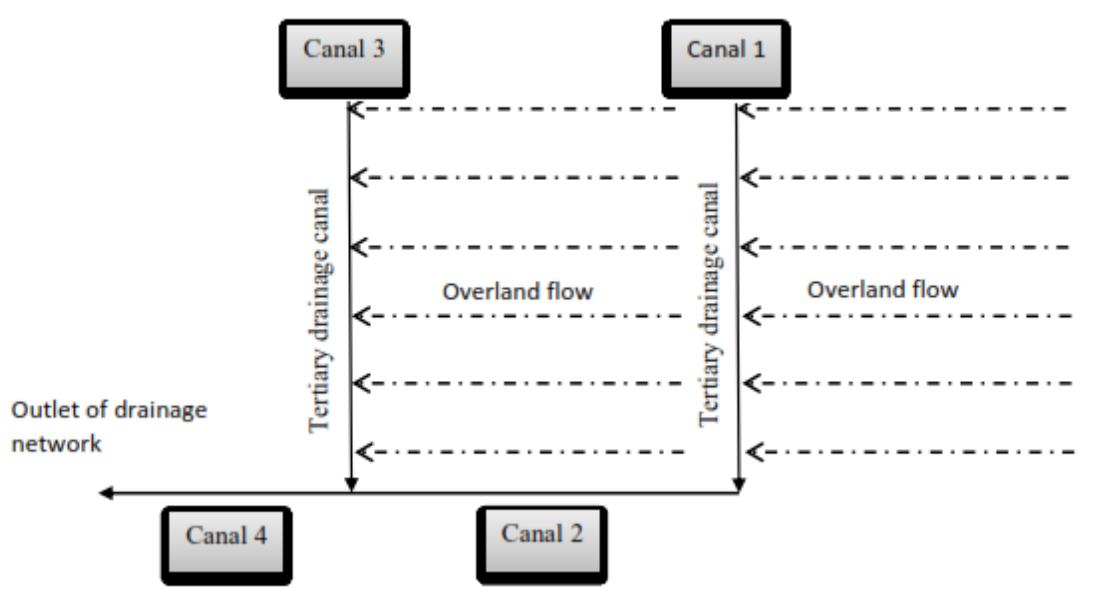

Figure 1. Drainage network of two tertiary canals (numbered 1 and 3 ) and two parts of one secondary canal (numbered 2 and 4 )

The MacCormack scheme is an explicit, two-step predictor-corrector scheme that is second-order accurate in space and time and is capable of capturing the shocks without isolating them (Chaudhry, 2008). The predictor and corrector step of MacCormack scheme have the following forms:

\section{Predictor step:}

$U_{k}^{* j+1}=U_{k}^{j}-\frac{\Delta t}{\Delta x}\left(F_{k}^{j}-F_{k-1}^{j}\right)+S_{k}^{j} \Delta t$

\section{Corrector step:}

$U_{k}^{j+1}=\frac{1}{2}\left(U_{k}^{j}+U_{k}^{* j+1}-\frac{\Delta t}{\Delta x}\left(F_{k+1}^{* j+1}-F_{k}^{* j+1}\right)+S_{k}^{* j+1} \Delta t\right)$

where $\mathrm{k}$ represents spatial node, $\mathrm{j}$ represents time, and ${ }^{\mathrm{k}} \mathrm{j}+1$ refers to variables computed during the predictor part.

In case of the diffusion model, apart from the above equations, the Manning equation is also required, which for the predictor step is written as follows:

$Q_{k}^{* j+1}=\frac{1}{n} A_{k}^{* j+1}\left(R_{u k}^{*}{ }^{* j+1}\right)^{2 / 3}\left(S_{o}-\frac{y_{k}^{* j+1}-y_{k-1}^{*}{ }^{j+1}}{\Delta x}\right)^{1 / 2}$

where $R_{u}$ is the hydraulic radius

Additional the Manning equation for the corrector step has the form:

$Q_{k}^{j+1}=\frac{1}{n} A_{k}^{j+1}\left(R_{u k}^{j+1}\right)^{2 / 3}\left(S_{o}-\frac{y_{k+1}^{j+1}-y_{k}^{j+1}}{\Delta x}\right)^{1 / 2}$

Similarly, in case of the kinematic model, the equation of Manning is also required, and it is written for both the predictor and corrector step, as follows:

$$
\begin{aligned}
& Q_{k}^{* j+1}=\frac{1}{n} A_{k}^{* j+1}\left(R_{u k}^{* j+1}\right)^{2 / 3}\left(S_{o}\right)^{1 / 2} \\
& Q_{k}^{j+1}=\frac{1}{n} A_{k}^{j+1}\left(R_{u k}^{j+1}\right)^{2 / 3}\left(S_{o}\right)^{1 / 2}
\end{aligned}
$$




\section{INITIAL AND BOUNDARY CONDITIONS}

For the simulation of flow routing in a system of drainage canals, in addition to the two differential equations (continuity equation and momentum equation), the initial and the boundary conditions are also required. As Figure 2 shows, apart from external boundary conditions at points $A, B$ and $C$, the interior boundary conditions at the junction point $m$ of drainage ditches should be defined.

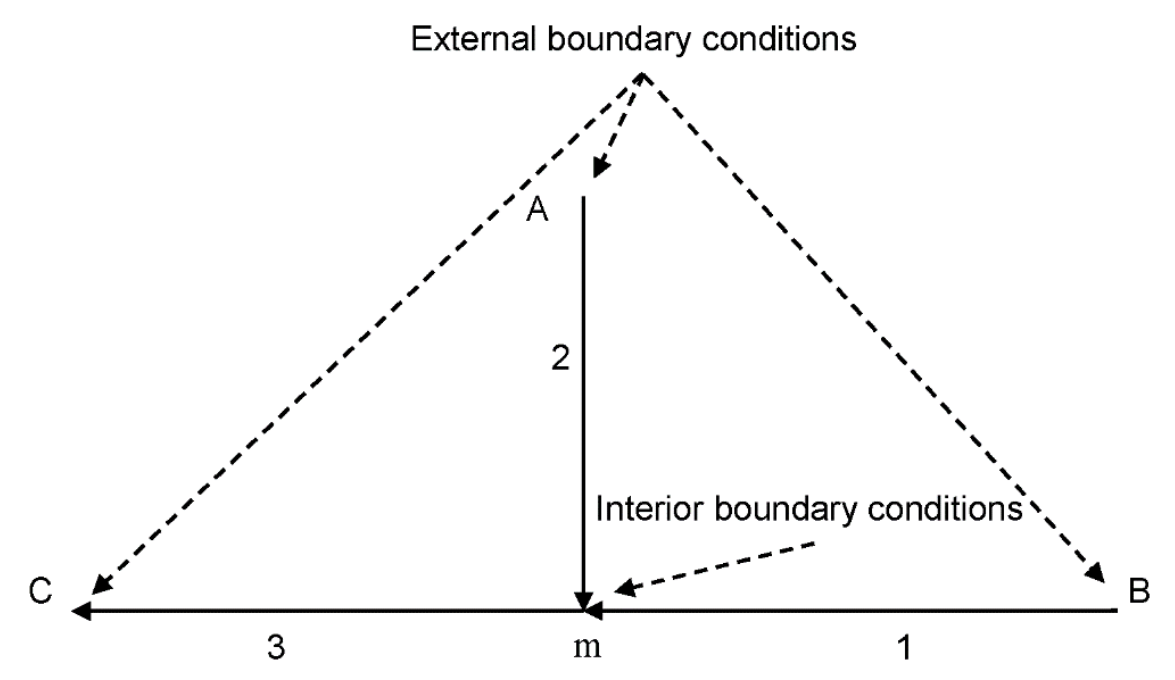

Figure 2. Drainage network with interior and external boundary conditions

At this point, the positive characteristic equation is applied at the end node of the ditch numbered 1 , as well as at the end node of the ditch numbered 2, as equation (6) shows:

$$
\mathrm{C}^{+}: \mathrm{Q}_{\mathrm{m} 1,2}=\mathrm{f}\left(\mathrm{y}_{\mathrm{m}}\right)
$$

Also the negative characteristic equation is applied at the first node of the ditch numbered 3 , which is written as:

$C^{-}: y_{m}=f\left(Q_{m 3}\right)$

It is mentioned that the flow is directed from the ditches 1 and 2 to the ditch 3 . Also it is assumed that the flow depth at the end node of ditches 1 and 2 is equal to that in the first node of ditch 3 . This follows from the energy equation where the velocity head and the head-loss terms are considered small and may be neglected. From the continuity equation, it follows that the discharge in the first node of the ditch 3 is equal to the sum of discharges of the two other ditches (1 and 2) at their last node, which is written as:

$\mathrm{Q}_{\mathrm{m} 3}=\mathrm{Q}_{\mathrm{m} 1}+\mathrm{Q}_{\mathrm{m} 2}$

Equations 6,7 and 8 are simultaneously solved to give the flow depth at the junction point of three ditches and the discharges of the three ditches at the same time step.

The external boundary conditions at the points $A$ and $B$ are described by the following equation:

$Q_{A, B}=Q_{A, B \text { initial }}$

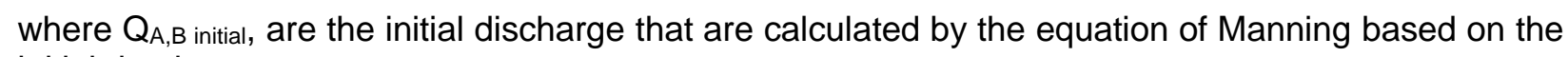
initial depth.

The equations $(10 \mathrm{a}, 10 \mathrm{~b})$ are used at the downstream end of the ditch 3 :

$$
\begin{aligned}
& \left(\frac{\partial y}{\partial x}\right)_{k-1}^{j}=\left(\frac{\partial y}{\partial x}\right)_{k}^{j} \\
& \left(\frac{\partial Q}{\partial x}\right)_{k-1}^{j}=\left(\frac{\partial Q}{\partial x}\right)_{k}^{j}
\end{aligned}
$$

where $\mathrm{k}$ represents spatial node and $\mathrm{j}$ represents time 
Finally, in order to avoid floating point errors in numerical solution of the Saint-Venant equations, the initial flow depth is assumed to be equal to a very small value. This may be considered that is the result of the existence of groundwater flow to the drainage ditches.

\section{STABILITY CRITERIA}

The time step in the MacCormack scheme, like other explicit schemes, must satisfy the CourantFriedrich-Lewy (CFL) stability criterion:

$$
\Delta \mathrm{t} \leq \mathrm{C}_{\mathrm{n}} \frac{\Delta \mathrm{x}}{(|\mathrm{U} \pm \mathrm{C}|)_{\max }}
$$

where $C_{n}$ is the CFL number and $C$ is the celerity of small disturbances.

However, in case of flow with very small depth values and large roughness coefficient values, the criterion of CFL is not sufficient to assure stability of the MacCormack scheme. Terzidis, 1968 by applying the John von Neumann stability analysis to the simple diffusion type explicit computational scheme showed that two criteria are required to assure stability. For flows with small depth values and large roughness coefficient values the dominant criterion seems to be the friction criterion. For the studied case the friction criterion takes the following form (Pantelakis 2010, Pantelakis et al., 2011):

$$
\Delta \mathrm{t} \leq \frac{\mathrm{AR}_{\mathrm{u}}^{4 / 3}}{\mathrm{gn}^{2} \mathrm{Q}}
$$

\section{APPLICATIONS AND RESULTS}

In order to examine the accuracy of the proposed models, the dynamic model was compared with the model presented in the research work of Aral et al., 1996. They approximated the flow routing in a channel network consisted by three, prismatic, rectangular channels without lateral flow such as Figure 2 shows. The main characteristics of the channel network are given in the Table 1.

Table 1. Input data for the channel network of Aral et al. (1996)

\begin{tabular}{llll}
\hline & Channel 1 & Channel 2 & Channel 3 \\
\hline Length & $5000 \mathrm{~m}$ & $5000 \mathrm{~m}$ & $5000 \mathrm{~m}$ \\
\hline Bottom width & $50 \mathrm{~m}$ & $50 \mathrm{~m}$ & $100 \mathrm{~m}$ \\
\hline Slope & 0.0002 & 0.0002 & 0.0002 \\
\hline Manning coef. & 0.025 & 0.025 & 0.025 \\
\hline Initial depth & $1.43 \mathrm{~m}$ & $1.43 \mathrm{~m}$ & $1.43 \mathrm{~m}$ \\
\hline Initial discharge & $50 \mathrm{~m}^{3} \mathrm{sec}^{-1}$ & $50 \mathrm{~m}^{3} \mathrm{sec}^{-1}$ & $100 \mathrm{~m}^{3} \mathrm{sec}^{-1}$ \\
\hline
\end{tabular}

Aral et al. (1996) solved the Saint-Venant equations with the relaxation scheme and compared their results with those of a model based on the numerical solution of the Saint-Venant equations with an implicit scheme. In this research work, the proposed dynamic model was compared with the model of Aral et al. (1996) in order to assess the reliability of the proposed hydraulic models. As it is obvious from Figure 3, the results of the proposed dynamic model are very close to the results obtained by the relaxation scheme of Aral et al. (1996).

The diffusion and kinematic models were also applied for the same channel network of Aral et al., 1996. Figure 4 shows that the diffusion model give results that differ from those of the proposed dynamic model especially at the area of the peak discharge. The maximum rate of discharge computed by the dynamic model was $150 \mathrm{~m}^{3} \mathrm{sec}^{-1}$ and it was occurred after $5970 \mathrm{sec}$ from the beginning of flow. The respective values for the diffusion model were $145 \mathrm{~m}^{3} \mathrm{sec}^{-1}$ and $6374 \mathrm{sec}$. Moreover the two models required different values of Courant number for their convergence. The dynamic model converged for $C_{n}=0.8$ and the diffusion model for $C_{n}=0.05$. The kinematic model was not converged for any value of Courant number due to the low slope of canals.

In order to evaluate the effect of the slope value to the hydrographs formation, the proposed models have also been compared for higher slope values $\left(S_{0}=0.001\right.$ and $\left.S_{0}=0.005\right)$ for the same channel network of Aral et al., 1996. Figures 5 and 6 show that the two models, dynamic and diffusion, have 


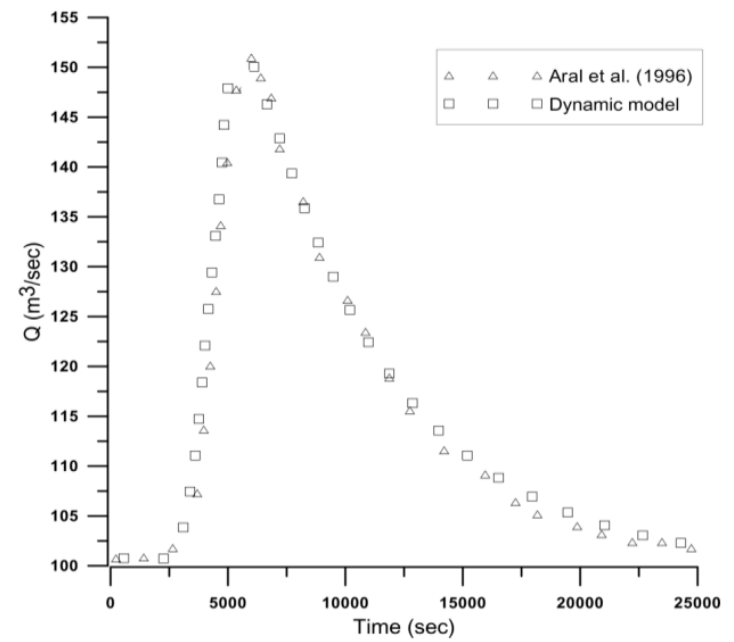

Figure 3. Hydrographs at the downstream end of the channel network calculated by the dynamic model and the model of Aral et al. (1996)

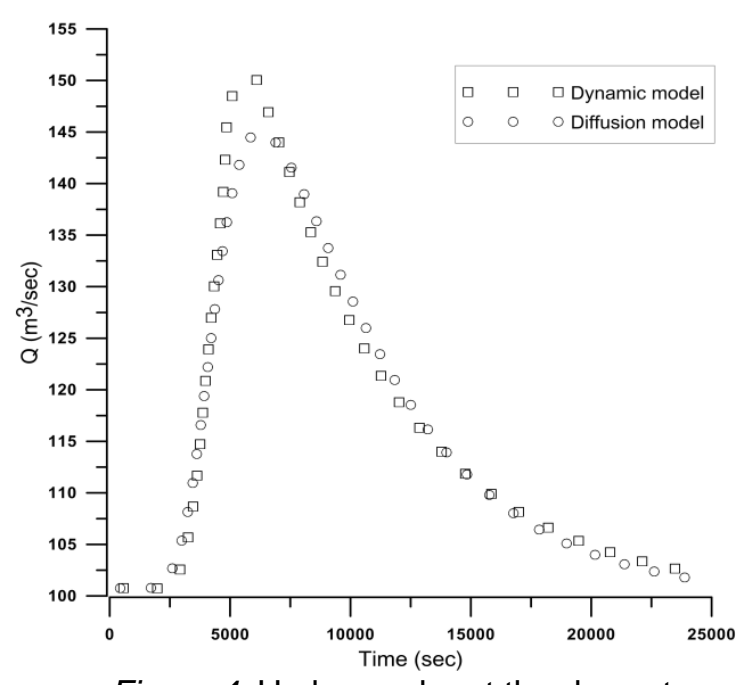

Figure 4. Hydrographs at the downstream end of the channel network calculated by the dynamic and the diffusion models for the application of Aral et al. (1996)

almost identical results for both slope values. In the case of the slope $S_{0}=0.001$, the maximum rate of discharge, the time that it was occurred and the Courant number were $214 \mathrm{~m}^{3} \mathrm{sec}^{-1}, 5990 \mathrm{sec}$ and 0.8 for the dynamic model, and $211 \mathrm{~m}^{3} \mathrm{sec}^{-1}, 5720 \mathrm{sec}$ and 0.2 for the diffusion model, respectively. In the case of the slope $S_{0}=0.005$, these values were $281 \mathrm{~m}^{3} \mathrm{sec}^{-1}, 4251 \mathrm{sec}$ and 0.8 for the dynamic model, and $280 \mathrm{~m}^{3} \mathrm{sec}^{-1}, 4233 \mathrm{sec}$ and 0.5 for the diffusion model, respectively. As it is obvious from the Figures 5 and 6 the accuracy of the proposed dynamic and diffusion models depends on the slope of channels. Their results are almost identical as the slope of channels become steeper. Also it was found that the kinematic model was not converged for the channel slope $S_{0}=0.001$ and only in case of the stepper slope $S_{0}=0.005$ gave results that were almost identical with the results of the two other proposed models. Nevertheless, the maximum rate of discharge was $292 \mathrm{~m}^{3} \mathrm{sec}^{-1}$ and occurred after $4233 \mathrm{sec}$ from the beginning of the flow. The Courant number value was 0.5.

In addition, all the proposed models were applied in case of a drainage network consisted by four drainage canals with tertiary canals receiving as lateral inflow the overland flow from irrigated fields, as Figure 1 shows. The overland flow caused by intense rainfalls has been simulated by runoff models based on Saint-Venant equations (Pantelakis, 2010).

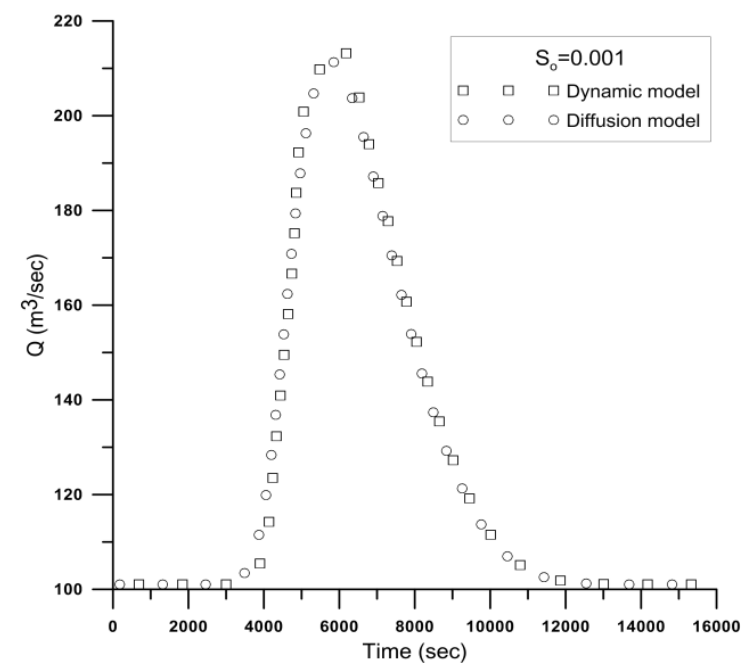

Figure 5. Hydrographs at the downstream end of the channel network calculated by the dynamic model and the diffusion model for channel slope $\mathrm{So}=0.001$

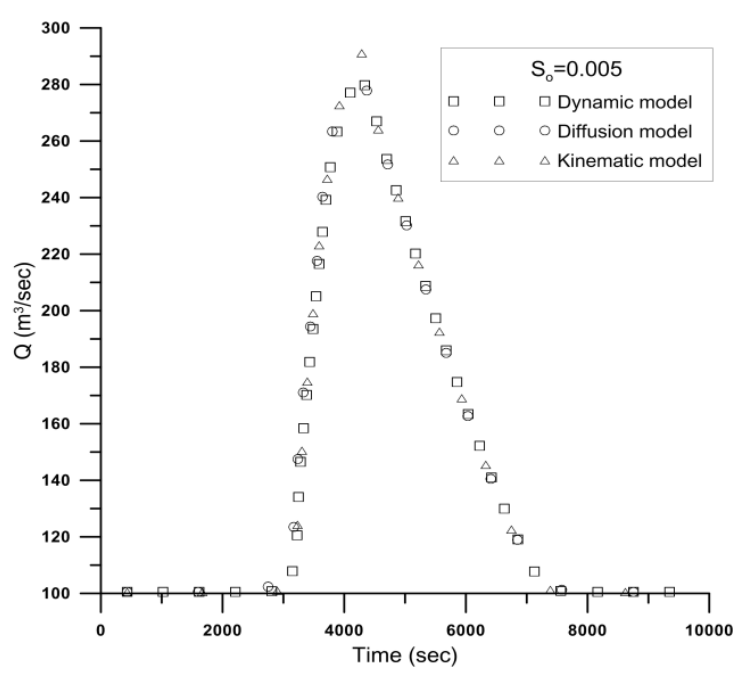

Figure 6. Hydrographs at the downstream end of the channel network calculated by the dynamic, the diffusion and kinematic model for channel slope So $=0.005$ 
Main characteristics of this kind of drainage network are the small bed slope of canals $\left(S_{0}<0.0004\right)$ and the length of the tertiary canals. Their length determines mainly the geometrical and the hydraulic characteristic of the entire drainage network. As we have mentioned above, the channel slope affect significantly the accuracy of the hydraulic models. A similar effect has the length of the tertiary ditches as it can be seen in Figures 7 and 8 . These results were derived for a Manning roughness coefficient value $n=0.1$. This value means that the drainage canals are poorly maintained. The bed slope of the tertiary canals is $S_{01,3}=0.0003$ and the bed slope of the canals 2 and 4 is $\mathrm{S}_{02,4}=0.0004$.

The maximum rate of discharge, the time to peak and the Courant number of the dynamic and diffusion models are given in Table 2 .

Table 2. The maximum rate of discharge, the time to peak and the Courant number of the two models for different lengths of the tertiary ditches 1,3

\begin{tabular}{ccccc}
\hline & \multicolumn{2}{c}{ Length $_{1,3}=1000 \mathrm{~m}$} & \multicolumn{2}{c}{ Length $_{1,3}=2000 \mathrm{~m}$} \\
\cline { 2 - 5 } & $\begin{array}{c}\text { Dynamic } \\
\text { model }\end{array}$ & Diffusion model & Dynamic model & Diffusion model \\
\hline Qmax & $0.630 \mathrm{~m}^{3} \mathrm{sec}^{-1}$ & $0.603 \mathrm{~m}^{3} \mathrm{sec}^{-1}$ & $0.993 \mathrm{~m}^{3} \mathrm{sec}^{-1}$ & $0.989 \mathrm{~m}^{3} \mathrm{sec}^{-1}$ \\
\hline Time & $18663 \mathrm{sec}$ & $18489 \mathrm{sec}$ & $19150 \mathrm{sec}$ & $19068 \mathrm{sec}$ \\
\hline Courant number & 0.5 & 0.01 & 0.5 & 0.01 \\
\hline
\end{tabular}

Figures 7 and 8 show that the results of the two models become closer to each other as the length of the tertiary ditches changes from $1000 \mathrm{~m}$ to $2000 \mathrm{~m}$. Also the Courant number value of diffusion model becomes lower (0.01) in both cases. Moreover, the kinematic model was not converged due to the small slope of the ditches. For a lower Manning roughness coefficient value $n=0.03$, which has the same result as a lower bed slope value, the diffusion model may not converge or it may require a Courant number value lower than 0.01 .

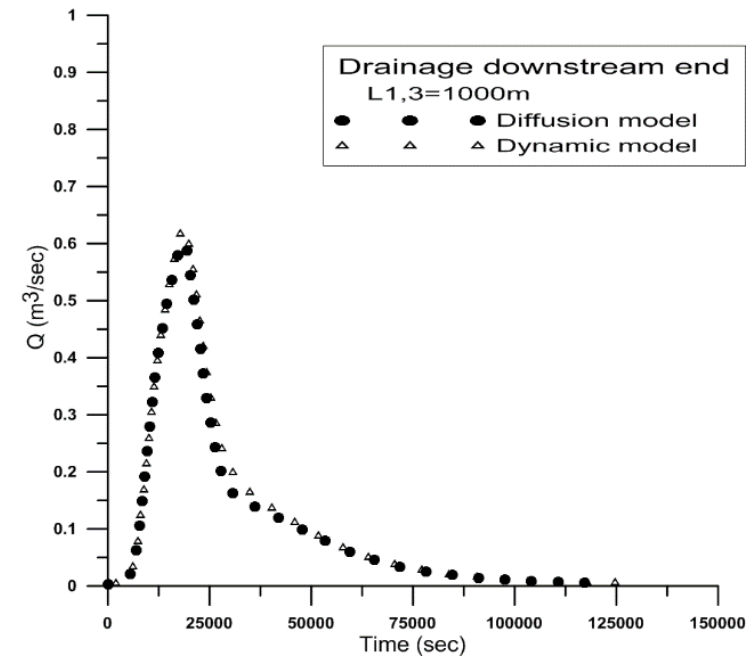

Figure 7. Hydrographs at the downstream end of a drainage network where the length of tertiary ditches is $1000 \mathrm{~m}$ and Manning coefficient is $\mathrm{n}=0.1$

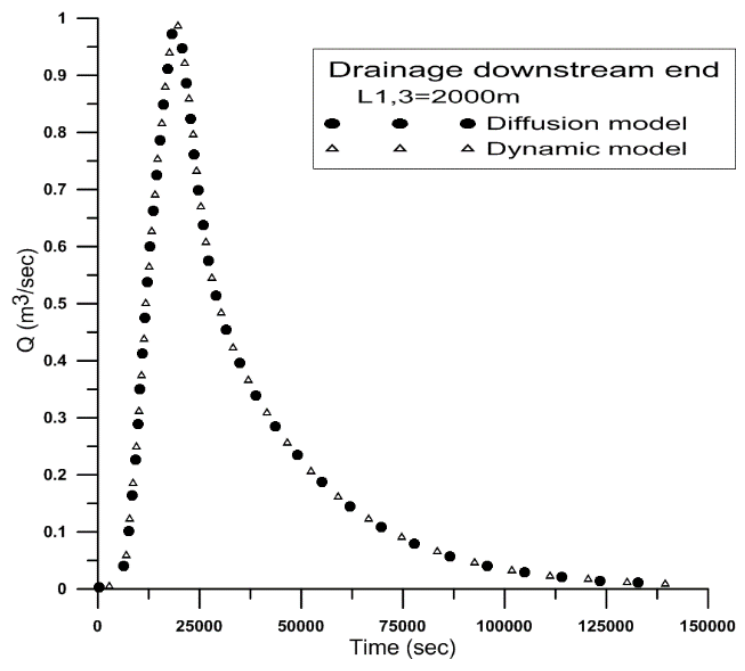

Figure 8. Hydrographs at the downstream end of a drainage network where the length of tertiary ditches is $2000 \mathrm{~m}$ and Manning coefficient is $n=0.1$

Figures 9 through 12 present the results of the proposed dynamic model for both values of Manning roughness coefficient $(n=0.1$ and $n=0.03)$ and for both values of tertiary canals' length $\left(L_{1}, 3=2000 \mathrm{~m}\right.$ vs $L 1,3=1000 \mathrm{~m}$ ). The lower value of Manning means that the drainage systems of canals are well preserved. Figures 11 and 12 present the computed depth values for the above cases. 


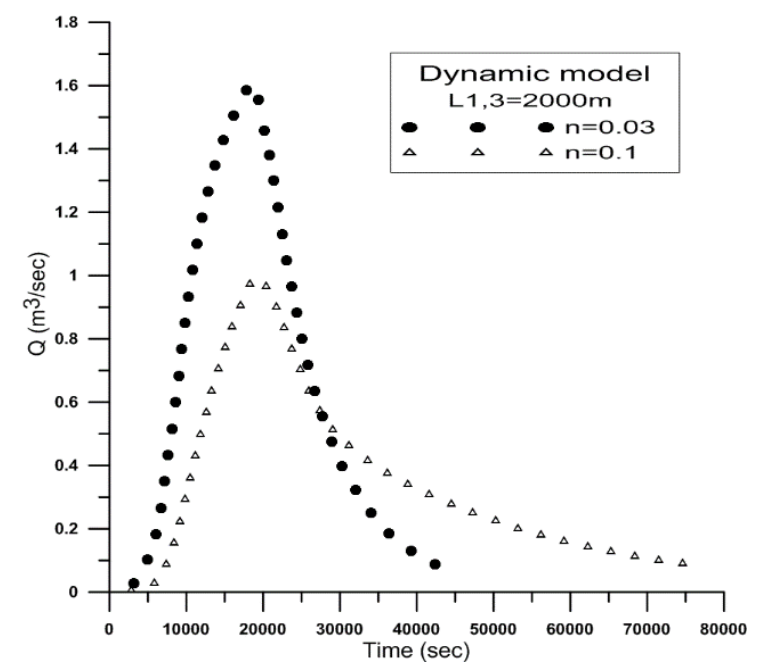

Figure 9. Hydrographs derived by dynamic model at the downstream end of a drainage network where the length of tertiary ditches is $2000 \mathrm{~m}$ and for both value of Manning coefficients $n=0.03$ and $\mathrm{n}=0.1$

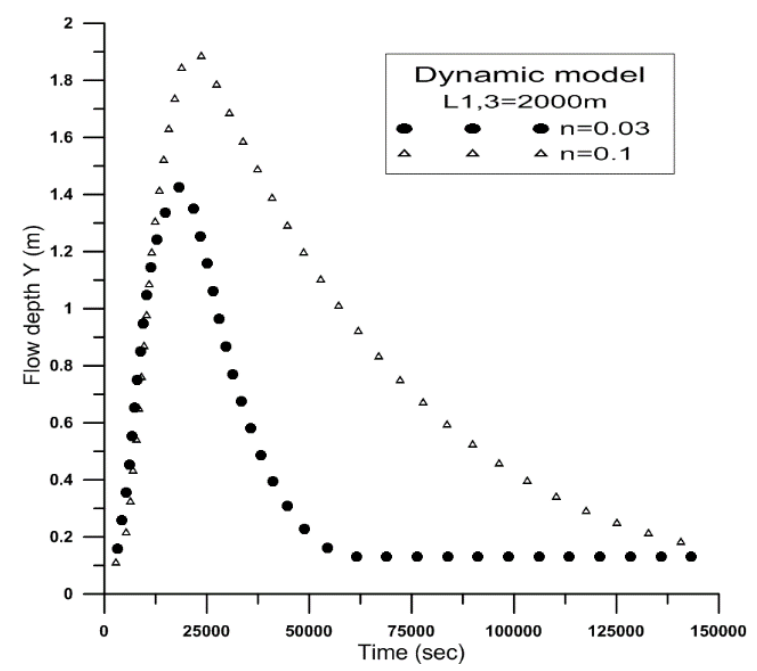

Figure 11. Flow depth values derived by dynamic model at the downstream end of a drainage network where the length of tertiary ditches is $2000 \mathrm{~m}$ and for both value of Manning coefficients $\mathrm{n}=0.03$ and $\mathrm{n}=0.1$

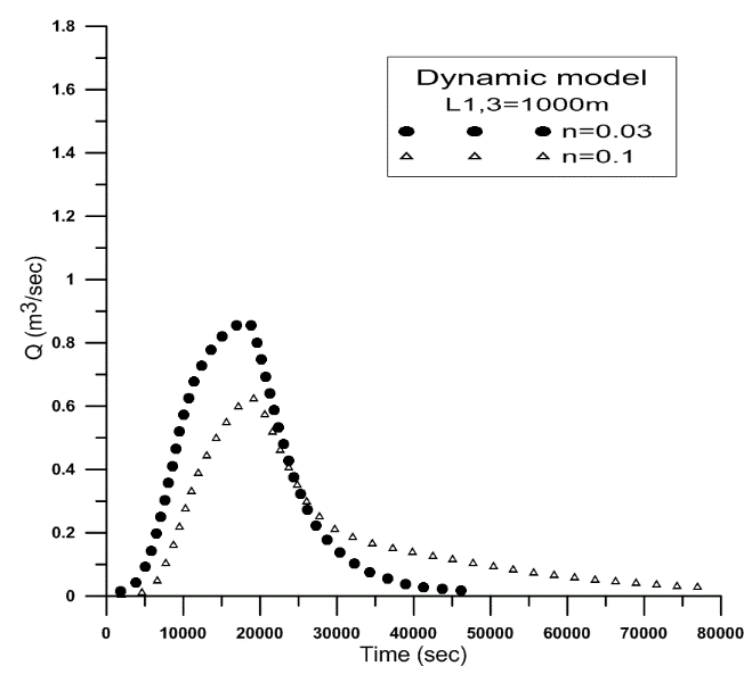

Figure 10. Hydrographs derived by dynamic model at the downstream end of a drainage network where the length of tertiary ditches is $1000 \mathrm{~m}$ and for both value of Manning coefficients $n=0.03$ and $n=0.1$

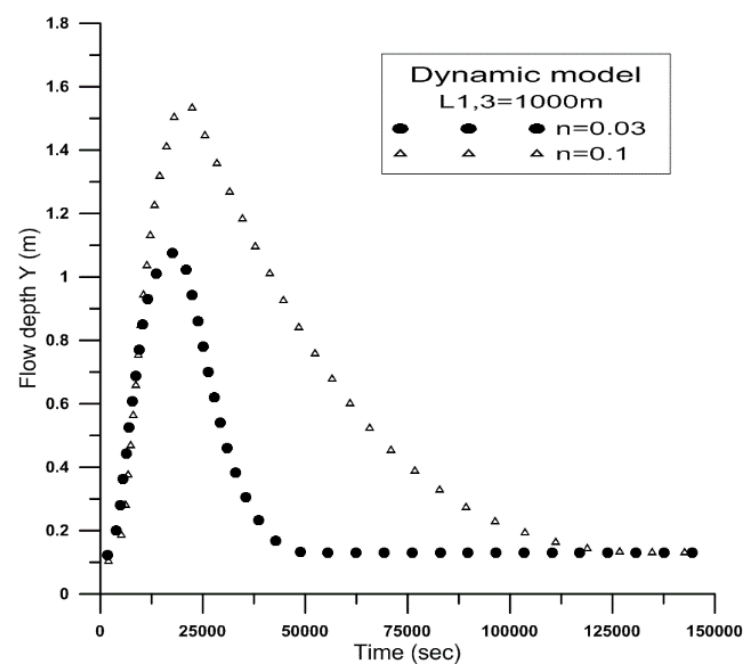

Figure 12. Flow depth values derived by dynamic model at the downstream end of a drainage network where the length of tertiary ditches is $1000 \mathrm{~m}$ and for both value of Manning coefficients $n=0.03$ and $\mathrm{n}=0.1$

From Figures 9, 10, 11 and 12, it is observed that the lower value of the Manning coefficient resulted in large discharge values with small flow depth values. The maximum discharge rate is increased $61 \%$ for the length of tertiary ditches $L_{1,3}=2000 \mathrm{~m}$ and $38 \%$ for the second case of tertiary ditches $\mathrm{L}_{1,3}=1000 \mathrm{~m}$. As far as the flow depth values are concerned, the reduction is about $25 \%$ for the first case and is about $30 \%$ for the second case. Moreover the lower value of Manning coefficient leads to a shorter base of hydrographs. This means that the increasing and the reduction of the discharge completed in a short time but with lower flow depths. 


\section{CONCLUSIONS}

The basic conclusions drawn for this research are concentrated on:

1. Models based on the numerical solution of the Saint-Venant equations with the explicit MacCormack computational scheme can be effectively used instead of complicated implicit schemes for the simulation of flow routing in a network of drainage canals.

2. The accuracy of the diffusion model and the kinematic model to predicting flow in a channel network depends on the geometrical characteristics of the channels, such as the bed slope and the length. The results of these models are closer to those of the dynamic model as the bed slope and the length of the channels increase.

3. In case of a system of drainage canals within surface irrigation system where the bed slopes of the ditches are very small, the kinematic model seems to be less effective for the simulation of flow routing. Moreover the kinematic model is not able to simulate the backwater effects which often occur in this kind of canal networks.

4. The diffusion model may give results almost identical with those of the dynamic model but it requires small Courant number values, which has as a consequence longer execution time. This problem may be important in case of a huge drainage network.

5. The lower value of Manning coefficient leads to higher values of discharge and lower value of flow depths. This means that proper maintenance of the system of drainage canals is crucial for its response to safely convey the excess water.

\section{REFERENCES}

Akan A.O. (1985), Kinematic-Wave Method for Peak Runoff Estimates, J. of Transp. Eng., 111(4), 419425

Aral M.M., Zhang Y. and Jin S. (1996), A Computational Method for Wave Propagation Simulation in Open-Channel Networks, Multimedia Environmental Simulations Laboratory, Georgia Tech, Report No. MESL-03-96, $56 \mathrm{p}$.

Chaudhry M.H. (2008), Open channel flow, Springer edition, NY

Chen C.N., Tsai C.H. and Tsai C.T. (2007), Reduction of discharge hydrograph and flood stage resulted from upstream detention ponds, Hydrol. Process., 21(25), 3492-3506.

Islam A., Raghuwanshi N.S., Singh R. and Sen D.J. (2005), Comparison of gradually varied flow computation algorithms for open channel network, J. of Irrig. and Drain. Eng., A.S.C.E., 131(5), 457465.

Kesserwani G., Ghostine R., Vazquez J., Mose R., Abdallah M. and Ghenaim A. (2008), Simulation of subcritical flow at open channel junction, Adv. in Water Resour., 31(2), 287-297.

Naidu B.J., Bhallamudi S.M. and Narasimhan S. (1997), GVF computation in tree type channel networks, J. Hydraul. Eng., 123(8), 700-708.

Pantelakis D., Zissis T., Anastasiadou-Partheniou E. and Baltas E. (2011), Numerical models for the simulation of overland flow in fields within surface irrigation systems, Water Resour. Manage, doi 10.1007/s11269-011-9955-2

Pantelakis D (2010), Numerical models for the simulation of flow in systems of drainage canals within surface irrigation networks. Ph.D. Thesis, Aristotle University of Thessaloniki

Sen D.J. and Garg N.K. (2002), Efficient algorithm for gradually varied flows in channel networks, J. of Irrig. and Drain. Eng., A.S.C.E., 128(6), 351-357.

Singh V.P. (1996), Kinematic wave modeling in water resources, Surface Water Hydrology, John Wiley \& Sons Inc., New York

Terzidis G (1968), Discontinuous unsteady flow in open channels, Ph. D. Thesis, University of California 